\title{
ANÁLISE POR TOMOGRAFIA COMPUTADORIZADA DO ENXERTO AUTÓGENO NA CIRURGIA DE "SINUS LIFT"*
}

\author{
Sérgio Aron Ajzen ${ }^{1}$, Rafael Andrade Moscatiello ${ }^{2}$, Aida Maria Custódio de Lima ${ }^{2}$, \\ Vitória Aparecida Muglia Moscatiello ${ }^{2}$, Rafael Muglia Moscatiello ${ }^{3}$, Celso Itiro Nishiguchi ${ }^{3}$, \\ Maria Teresa de Seixas Alves ${ }^{4}$, Helio Kiitiro Yamashita ${ }^{5}$
}

Resumo OBJETIVO: Quantificar a formação óssea nos enxertos com e sem plasma rico em plaquetas, obtido pelos métodos de centrifugação e aférese, comparando os três tipos de enxertos realizados por meio de análise tomográfica. MATERIAIS E MÉTODOS: Este estudo prospectivo, duplo cego, utilizou uma amostra composta de 34 pacientes adultos, de ambos os sexos, com idade média de 48 anos e 8 meses, portadores de pneumatização unilateral ou bilateral dos seios maxilares, que necessitavam de enxertos ósseos, com a finalidade de melhorar as condições locais para a colocação dos implantes dentários. Todos os pacientes realizaram tomografia computadorizada antes da cirurgia. Foram operados 53 seios maxilares, divididos em três grupos: enxerto de plasma rico em plaquetas obtido pelos métodos de aférese, centrifugação e enxerto apenas de osso autógeno. Após seis meses do procedimento cirúrgico foram realizados novos exames de imagem. RESULTADOS: Pela avaliação tomográfica, houve crescimento em altura e em largura nos três grupos quando foram comparados os momentos inicial e final, entretanto, não houve diferença estatística para a altura e para a largura. CONCLUSÃO: Evidências clínicas demonstram a eficácia dos enxertos autógenos, principalmente os associados a fatores indutores de crescimento ósseo, como o plasma rico em plaquetas, recuperando o arcabouço maxilofacial, necessário para a reconstrução protética e funcional por meio de implantes dentários.

Unitermos: Tomografia computadorizada por raios X; Seio maxilar; Enxerto ósseo; Plaquetas; Aférese.

Abstract Computed tomography evaluation of autogenous graft in sinus lift surgery.

OBJECTIVE: To quantify bone formation within autogenous bone grafts and autogenous bone grafts in combination with platelet-rich plasma obtained either from aphaeresis or centrifugation using computed tomography. MATERIALS AND METHODS: This prospective, double-blind study was conducted in 34 male and female adult patients (mean age of 28 years and 8 months), with either unilateral or bilateral pneumatization of the maxillary sinuses, requiring bone graft for dental implant. All patients were submitted to computed tomography examinations prior and six months after sinus lift surgery. Fifty-three maxillary sinuses were operated and divided into three distinct groups: autogenous bone graft, autogenous bone graft in combination with platelet-rich plasma obtained by centrifugation, and autogenous bone graft in combination with platelet-rich plasma obtained by aphaeresis. RESULTS: Computed tomography demonstrated bone growth in height and width between the initial and the follow-up computed tomography scans in all three groups. However, no statistical difference was found either for bone height or width. CONCLUSION: Clinical evidence demonstrates the effectiveness of autogenous bone grafts, particularly when used in combination with bone growth factors such as platelet-rich plasma, which allow prosthetic and functional restoration of maxillofacial structures through fixation of dental implants.

Key words: Computed tomography; Maxillary sinus; Bone graft; Platelets; Aphaeresis.

\footnotetext{
* Trabalho desenvolvido no Departamento de Diagnóstico por Imagem (DDI) da Universidade Federal de São Paulo/Escola Paulista de Medicina (Unifesp/EPM) e na Clínica da Fundação para o Desenvolvimento Científico e Tecnológico da Odontolo gia da Faculdade de Odontologia da Universidade de São Paulo (FOUSP), São Paulo, SP. Parte da Tese de Doutorado de Rafael Andrade Moscatiello, pelo DDI-Unifesp/EPM.

1. Professor Adjunto Livre-Docente do DDI-Unifesp/EPM.

2. Pós-graduandos do DDI-Unifesp/EPM.

3. Pós-graduandos da Disciplina Técnica Operatória e Cirurgia Experimental da Unifesp/EPM.

4. Professora Adjunta, Chefe da Disciplina de Anatomia Patológica da Unifesp/EPM.

5. Professor Adjunto do DDI-Unifesp/EPM.

Endereço para correspondência: Dr. Rafael Andrade Moscatiello. Avenida Caxingui, 231, ap. 32, bloco B, Butantan. São Paulo, SP, 05579-000. E-mail: odontoband@hotmail.com.

Recebido para publicação em 18/12/2003. Aceito, após revisão, em 23/3/2004.
}

INTRODUÇÃO

Os implantes dentais estão sendo usados em grande número de pacientes edêntulos totais ou parciais, sendo excelente método de tratamento para se obter uma adequada reabilitação bucal. No entanto, o seu sucesso depende de uma quantidade mínima de tecido ósseo para a inserção do implante, com comprimento e espessura seguros, a fim de suportar as forças da oclusão. Esta condição nem sempre se faz presente, por isso, técnicas de aumento de re- bordo alveolar e de levantamento do assoalho do seio maxilar, "sinus lift", têm sido desenvolvidas, viabilizando desta forma a utilização dos implantes dentais ${ }^{(\mathbf{1})}$.

A literatura tem evidenciado e sugerido que quando há pneumatização acentuada do seio maxilar e reabsorção de rebordo alveolar, a técnica de "sinus lift", combinada com enxerto ósseo, faz com que a quantidade final de osso obtido se torne suficiente para a instalação de implantes dentais. O enxerto sinusal é um procedimento testado com resultados previsíveis, 
e seu sucesso é sempre alcançado quando se observa atentamente o protocolo correto para sua realização. Dentre os materiais utilizados, o osso autógeno tem demonstrado ser aquele que apresenta o padrão ideal para reconstruções desta região ${ }^{(2)}$.

A engenharia genética vem realizando estudos com a finalidade de desenvolver materiais que promovam a indução de fatores de crescimento, isto é, materiais com capacidade osteoindutora que estimulam as células indiferenciadas a se transformar em osteoblastos. Entre estes materiais, o plasma rico em plaquetas (PRP) tem-se evidenciado, devido à sua capacidade regenerativa. Ele tem-se mostrado eficiente nas cirurgias reconstrutivas da região oral, maxilofacial e implantodontia, principalmente quando associado a enxertos ósseos. Sua estratégia terapêutica fundamenta-se na modulação e aceleração dos processos cicatriciais, por meio dos fatores de crescimento contidos nas plaquetas, que são os iniciadores universais de quase todo o processo de reparação ${ }^{(\mathbf{3})}$. Para se conseguir a regeneração óssea, torna-se necessário que o osso substituto seja capaz de promover a ativação e a liberação dos fatores de crescimento. Portanto, deve-se associar ao enxerto fatores que estimulem a cicatrização e a reparação tecidual ${ }^{(4)}$.

As alternativas terapêuticas restauradoras na região buco-maxilo-facial buscam solucionar e melhor compreender os mecanismos dos processos de cicatrização e o desenvolvimento de novas técnicas de reconstrução utilizando enxertos ósseos. Porém, ainda nos dias atuais persiste a discussão sobre que tipo de osso seria ideal para ser utilizado como enxerto e a técnica mais adequada para obtê-lo.

Um dos pré-requisitos mais importantes para se obter o sucesso com implantes osteointegrados é a presença de uma quantidade suficiente de osso saudável no local receptor, incluindo não somente uma altura óssea adequada, mas também uma largura suficiente do osso basal remanescente. Quando o implante é colocado em uma região de osso neoformado, estimula a maturação e a remodelação óssea ${ }^{(5)}$.

Deve-se salientar que o êxito na implantologia oral depende principalmente do plano de tratamento realizado, com uma avaliação radiográfica apropriada do re- bordo ósseo edêntulo e do local em potencial que receberá o implante. Por meio de imagens apropriadas, como radiografias intra-orais, radiografia panorâmica, tomografia computadorizada (TC) e ressonância magnética (RM), o cirurgião avalia a quantidade e a qualidade óssea presentes e pode relacioná-las com as estruturas anatômicas subjacentes e internas ${ }^{(\mathbf{6})}$.

Os avanços tecnológicos ocorridos no diagnóstico por imagem, somados aos já existentes, têm promovido um novo impulso para o desenvolvimento da odontologia, principalmente com a introdução da TC. Antes do seu advento, o diagnóstico radiográfico odontológico utilizava principalmente radiografias periapicais, que apresentam limitações e restringem a visualização de áreas específicas, e radiografias panorâmicas, que produzem imagem bidimensional, apresentando uma sobreposição e interposição de estruturas e distorções verticais e horizontais. As telerradiografias laterais e as póstero-anteriores de face por algumas especialidades também devem ser citadas ${ }^{(\mathbf{6})}$.

A TC foi introduzida na medicina em 1972, e por sua capacidade tridimensional é considerada o recurso de imagem mais preciso na implantodontia oral. Por meio de programas específicos ela é capaz de gerar imagens tridimensionais, e com cortes específicos produz imagens de tamanho real do comprimento e da espessura do rebordo ósseo residual, relacionando-os com as estruturas anatômicas críticas ${ }^{(6)}$.

$\mathrm{Na}$ TC dental, as imagens das estruturas ósseas são captadas por um sensor e são trabalhadas, removendo-se as sobreposições das estruturas existentes em outros planos, facilitando assim a interpretação das imagens. A aquisição dessas imagens pode se dar por meio de cortes axiais seriados ou da técnica espiral, sendo que esta última reduz a dose de radiação e o tempo de exame, diminuindo o risco de movimentação do paciente. Após a realização dos cortes, o computador reconstrói as imagens, obtendo-se cortes transversais perpendiculares ao rebordo alveolar. Estas imagens são numeradas e podem ser localizadas por imagens axiais e panorâmicas ${ }^{(7)}$.

Chilvarquer e Chilvarquer ${ }^{(8)}$ salientam que a TC espiral ou helicoidal apresenta vantagens, por minimizar ou eliminar o tempo de exposição do paciente durante o procedimento, diminuir os artefatos que dificultam a interpretação das imagens e possibilitar a captura de 30 ou mais cortes com espessura de 0,5 e $1 \mathrm{~mm}$ em menos de um minuto.

A TC, além de permitir a avaliação precisa da quantidade, qualidade e densidade óssea disponíveis para a instalação de implantes orais, pode avaliar os resultados da cirurgia de elevação do assoalho do seio maxilar, identificando inclusive a invaginação dos tecidos moles nos locais de enxerto e diagnosticando doenças sinusais ${ }^{(9)}$.

Longo período de estudos clínicos tem demonstrado que o processo de reabsorção óssea que ocorre seguindo a perda dos dentes é quatro vezes maior na maxila do que na mandíbula. A reabsorção mais intensa ocorre imediatamente após a perda dos dentes, resultando em reabsorção e remodelação devido à ausência de carga funcional. A perda óssea vertical no processo alveolar prossegue em aproximadamente $0,1 \mathrm{~mm}$ por ano, podendo variar de indivíduo para indivíduo.

Observa-se que após a perda dos dentes superiores e a conseqüente redução das forças mastigatórias que incidem na maxila, as paredes dos seios maxilares vão gradualmente diminuindo, resultando no aumento do seu tamanho. Além disso, com o avanço da idade e após a perda dos dentes, a reabsorção do processo alveolar da maxila e do seio maxilar ocorre gradualmente, como consequiência da ausência das funções, resultando em pneumatização progressiva dos seios maxilares ${ }^{(\mathbf{1 0})}$. A colocação de implantes osteo-integrados exige rebordo alveolar com espessura mínima de $5 \mathrm{~mm}$ e altura mínima de $10 \mathrm{~mm}$. Após a perda dos dentes, a reabsorção óssea irreversível e progressiva pode muitas vezes impedir a colocação de implantes ${ }^{(\mathbf{1 1})}$.

A mais recente avaliação do edentulismo evidencia que a longo prazo ocorrem remodelação, reabsorção e progressiva pneumatização do seio maxilar, deixando apenas uma fina camada separando o seio maxilar da cavidade oral. Este fato tornase preocupante, porque se sabe que a altura média entre a crista do rebordo alveolar e o assoalho do seio maxilar sadio varia de 9,3 a 3,23 mm, e a largura varia de 13,8 a $0,80 \mathrm{~mm}^{(\mathbf{1 2})}$. 
Vários são os estudos que têm apresentado evidências clínicas da importância direta dos fatores de crescimento que promovem a possibilidade de reparação de grandes defeitos ósseos, quer sejam provocados por problemas sistêmicos ou por extensa reabsorção óssea devida a múltiplas perdas dentárias, impossibilitando que o melhor tratamento reabilitador seja realizado. Aprender a empregar formas combinadas dos fatores de crescimento e diferenciação encontrados no osso e nos tecidos da área de reparação permite controlar clinicamente a quantidade de osso disponível, para melhorar a colocação de implantes dentários, em locais com deficiências ósseas ${ }^{(\mathbf{1 3})}$. A eficácia e o uso específico de determinados fatores de crescimento podem se transformar em excelente método terapêutico ${ }^{(\mathbf{1 4})}$.

Não se pode deixar de salientar que para ocorrer formação óssea é necessário que o osso substituto seja capaz de promover a ativação e liberação dos fatores de crescimento $^{(6)}$.

Durante a pesquisa de um hemostático ideal para cirurgias de tecidos moles e ósseos, foi produzido um adesivo de fibrina, agente hemostático com propriedades adesivas, que demonstrou apresentar, durante as primeiras aplicações cirúrgicas, propriedades excelentes quando há falta de concentração fibrinógena. Mais pesquisas resultaram no gel de plaquetas autógeno criado no início dos anos $90^{(\mathbf{1 5})}$

O acréscimo de fibrina autógena aos enxertos de osso esponjoso, para reconstrução mandibular em 33 casos avaliados radiograficamente, sugeriu uma consolidação mais rápida do enxerto ${ }^{(\mathbf{1 5})}$. O conhecimento dos fatores de crescimento nos enxertos ósseos utilizando o PRP tem evidenciado que este fator, quando adicionado ao enxerto ósseo, produz aumento considerável da produção óssea em comparação com aqueles enxertos que não o contêm ${ }^{(\mathbf{1 6})}$.

Quanto à qualidade óssea, os enxertos de mento apresentam-se superiores aos de ilíaco, possivelmente devido à arquitetura original da região ${ }^{(\mathbf{1 7})}$.

Sabe-se que a perda de dentes posteriores leva a uma reabsorção gradativa do processo alveolar da região posterior da maxila, que geralmente é agravada pelo aumento de volume do seio maxilar, pro- vocando em casos extremos uma fusão entre o assoalho do seio maxilar e o processo alveolar. Com a finalidade de melhorar as condições do rebordo alveolar para a colocação de implantes e a reabilitação protética, enxertos ósseos autógenos e implantes osteointegrados foram instalados em um único estágio, por meio da elevação da membrana do seio maxilar ${ }^{(18)}$.

Pesquisando tratamentos realizados em 162 seios, com 353 implantes colocados, concluiu-se que enxertos ósseos realizados na cirurgia de "sinus lift" com osso autógeno para a inserção futura de implantes são uma modalidade que apresenta excelentes resultados a longo $\operatorname{prazo}^{(\mathbf{1 9})}$.

Usando TC, foi feita a reconstrução tridimensional de 38 seios maxilares para que pudesse ser medido o seu volume. Levaram-se em consideração as diferenças individuais de volume e reabsorção do osso enxertado, sendo que $5,46 \mathrm{~cm}^{3}$ foram necessários para um levantamento de $15 \mathrm{~mm}$ de seio maxilar e 7,96 $\mathrm{cm}^{3}$ foram necessários para um levantamento de $20 \mathrm{~mm}^{\text {(20)}}$.

O objetivo deste trabalho é quantificar, por meio da TC, a formação óssea nos enxertos realizados apenas com osso autógeno e nos enxertos com osso autógeno e PRP obtido pelos métodos de centrifugação e aférese, comparando, seis meses depois, os três tipos de enxertos realizados.

\section{MATERIAIS E MÉTODOS}

Este estudo prospectivo, duplo cego multicêntrico, utilizou como amostra 34 pacientes adultos, de ambos os sexos (sete do sexo masculino e 28 do sexo feminino), sem distinção de raça, com idades entre 23 e 65 anos, idade média de 48 anos e 8 meses, que foram previamente avaliados por radiografias panorâmicas, nas quais se observou pneumatização unilateral ou bilateral dos seios maxilares relacionada às perdas dentárias e que necessitavam de enxertos ósseos, com a finalidade de melhorar as condições locais para a colocação dos implantes. Nestes 34 pacientes foram operados 53 seios maxilares, sendo a amostra dividida em três grupos: grupo aférese, pacientes que receberam enxerto de osso autógeno e PRP obtido pelo método de aférese; grupo centrífuga, pacientes que receberam enxerto de osso autóge- no e PRP obtido pelo método de centrifugação; e grupo osso autógeno, pacientes que receberam enxerto apenas de osso.

Todos os pacientes foram informados sobre os objetivos e procedimentos aos quais seriam submetidos, e assinaram um termo de consentimento livre e esclarecido. Foi preenchido um questionário de saúde, além de uma rigorosa anamnese que compreendia exame clínico intra e extrabucal e aferição da pressão arterial.

Os critérios de inclusão foram pacientes com boa saúde geral e bucal; pacientes com boa higiene bucal; que não estivessem usando medicações que interferissem nos fatores de coagulação ou de cicatrização; edêntulos totais ou parciais na maxila, portadores de pneumatização dos seios maxilares; com espaços protéticos adequados para a colocação dos implantes dentários; com disponibilidade para controle periódico.

Os critérios de exclusão foram pacientes com arcadas dentárias hígidas; com idade inferior a 23 anos; com a higiene bucal inadequada; com histórico de doenças ósseas; imunodeprimidos; que estivessem usando medicações que interferissem nos fatores de coagulação ou de cicatrização; portadores de discrasias sanguíneas; e pacientes com retardo no desenvolvimento psicomotor.

Todos os pacientes da amostra passaram por uma avaliação clínica, realizaram exames pré-operatórios laboratoriais de sangue, para comprovação real das condições de sua saúde geral, para poderem ser submetidos à cirurgia de elevação do assoalho do seio maxilar.

Foram realizados exames pré-operatórios radiográficos: radiografia periapical, radiografia panorâmica e TC. Esses exames foram repetidos seis meses após a intervenção cirúrgica, para a avaliação da quantificação óssea cortical e medular da região enxertada.

Uma mensuração óssea preliminar foi realizada com o uso de um espessímetro de toda a área edêntula. Os pacientes foram orientados a utilizar uma medicação de caráter preventivo uma hora antes da cirurgia, com capacidade antiinflamatória e antibiótica, e outra de caráter ansiolítico.

Foi feita uma TC inicial para a quantificação óssea, avaliação da extensão da 
pneumatização do seio maxilar e diagnóstico de possíveis doenças sinusais. Uma segunda TC, da mesma região, com o mesmo protocolo, foi realizada seis meses após para avaliar a formação óssea.

Foi utilizado aparelho de TC helicoidal Picker, modelo Select CT. O programa utilizado foi o Dentascan ${ }^{\circledR}$, que nos permite visualizar tridimensionalmente a maxila, avaliar o volume interno do seio maxilar e a espessura vestíbulo-palatina da área edêntula.

Para a obtenção da TC, o paciente foi colocado em decúbito dorsal na maca, de forma cômoda. Para a observação da maxila, a posição da cabeça do paciente obedeceu ao critério de manter o plano de Reidh (linha orbitomeatal) perpendicular à mesa de trabalho, e o plano sagital mediano, paralelo a ela. Os fatores físicos de exposição foram reduzidos, para obter resultados de alta resolução. Genericamente, trabalhamos com $120 \mathrm{kVp}$ e $50 \mathrm{~mA}$, com cortes de 1,0 mm de espessura e tempo médio de aquisição de 30 a 60 segundos.

As imagens foram reformatadas e reconstruídas com "software" Phillip ${ }^{\circledR}$ na “workstation" Ease Vision e documentadas em filmes para posterior análise.

As condições anatômicas apresentadas pelas imagens radiográficas definiram a quantidade de enxerto necessário e a área doadora. Nos casos em que havia necessidade de maior quantidade óssea foi escolhida a região da sínfise mandibular, devido às suas características fisiológicas e pela facilidade de acesso. Quando a pneumatização do seio maxilar não era tão extensa, o osso colhido foi proveniente da linha oblíqua externa da mandíbula, pelas suas características intramembranosas e por fornecer menor morbidade ao paciente.

Os aspectos anatômicos da maxila foram avaliados através de corte tomográfico panorâmico, em que foi observada e analisada a existência ou não de doenças; relacionaram-se os acidentes anatômicos com as áreas edêntulas; avaliou-se a integridade da cortical óssea que delimita o seio maxilar; diagnosticou-se a presença de septos ósseos; avaliou-se o remanescente alveolar, e sua densidade; detectou-se a presença de defeitos ósseos e classificou-se o grau de pneumatização do seio maxilar.
Para se quantificar o rebordo ósseo, foi traçada uma linha horizontal paralela ao plano de Camper e uma linha vertical paralela à parede lateral da fossa nasal, definindo a menor e a maior altura óssea vertical inicial (Figuras1A e 1B). Em seguida, no corte coronal, se mensurou a menor altura vertical inicial (Figura 2A) e a maior altura vertical inicial do remanescente ósseo (Figura 2B), entre a cortical alveolar e a cortical do seio maxilar. A maior e menor espessuras do rebordo ósseo inicial (vestíbulo-palatina) também foram mensuradas neste mesmo corte, traçando-se uma linha horizontal imediatamente abaixo da cortical inferior do seio maxilar (Figuras $2 \mathrm{~A}$ e $2 \mathrm{~B}$ ). Essas mensurações foram repetidas na TC realizada seis meses após a cirurgia, para quantificar a menor e a maior altura óssea vertical e espessura final do osso obtido (Figuras 1C, 1D, 2C e 2D).

Para analisar o crescimento ósseo, obtiveram-se as médias e os desvios-padrão (que mede a variabilidade dos dados) para a altura e a largura, considerando os três grupos (aférese, centrífuga e osso autógeno) e as diferenças entre as medidas finais
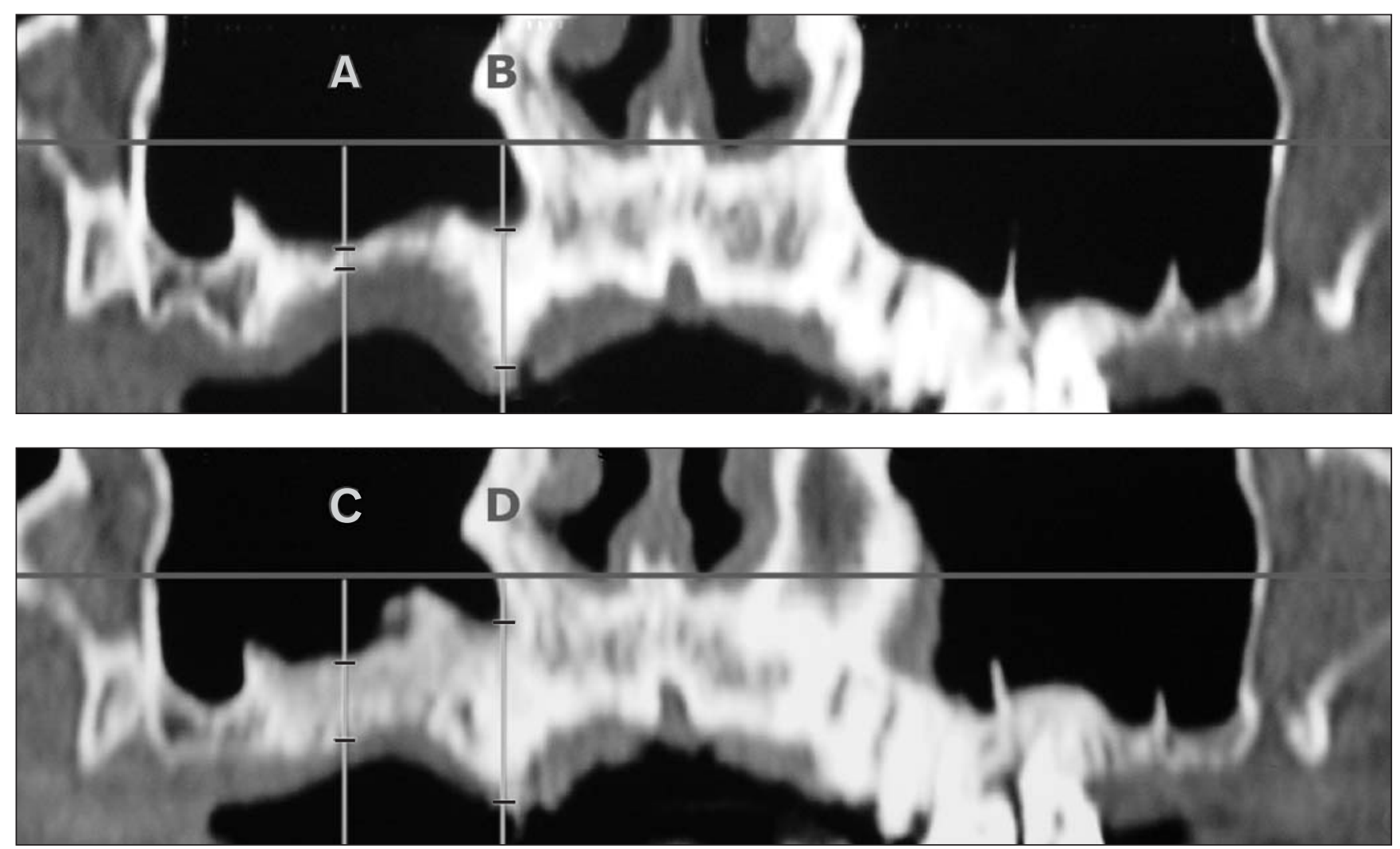

Figura 1. Menor (A) e maior (B) espessura óssea remanescente. Em $\mathbf{C}$ e $\mathbf{D}$, após a enxertia. 

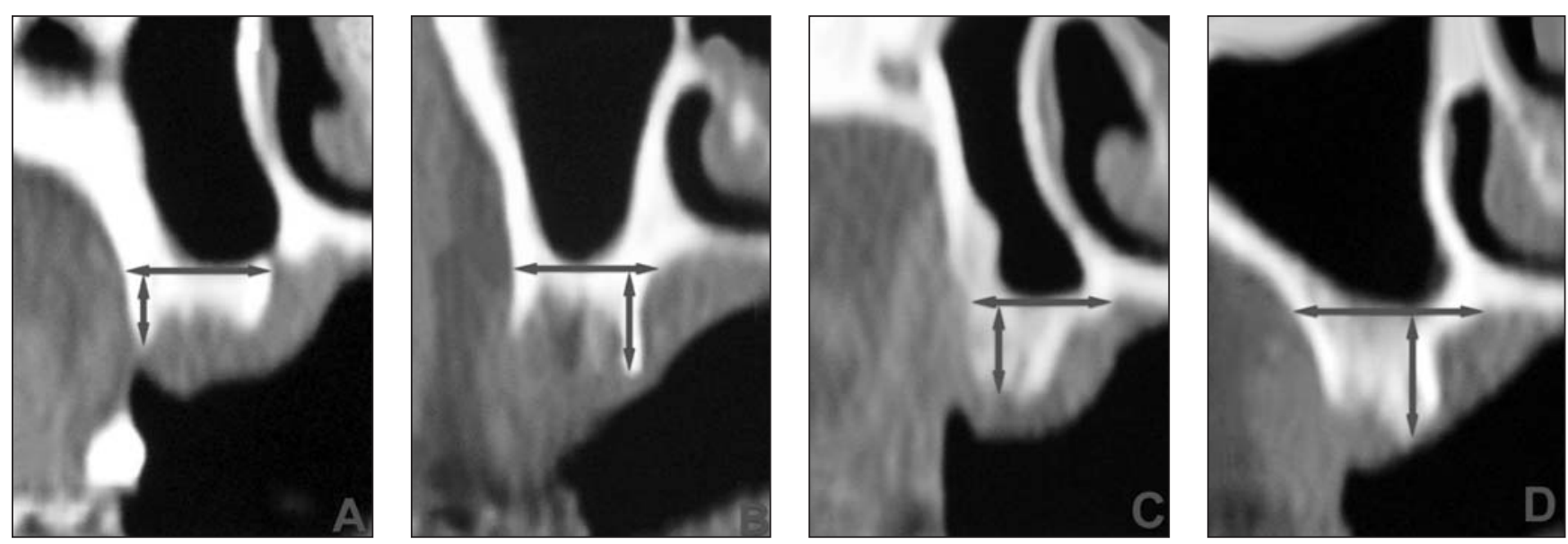

Figura 2. Mensuração da altura e largura inicial em A e B. Em C e D, após o enxerto.

e iniciais. Para verificar se existe diferença significativa entre os crescimentos médios, foi feita a análise de variância para medidas repetidas (ANOVA).

O nível de significância (p) foi fixado em um valor menor ou igual a $0,05(5 \%)$ para a rejeição da hipótese de nulidade.

\section{RESULTADOS}

Foram acompanhados 34 pacientes e 53 levantamentos de assoalho de seio maxilar, distribuídos conforme a Figura 3.

Verificamos que a região do mento foi a área doadora de maior eleição (Figura 4).

Para quantificar a formação óssea obtida nos enxertos após seis meses, o crescimento ósseo, tanto na largura quanto na altura, foi analisado comparando-se os três grupos segundo o tipo de enxerto utilizado.

Em relação à altura, assim como em relação à largura, podemos verificar que houve crescimento ósseo nos três grupos, como demonstram as Tabelas 1 e 2.

Pela avaliação da TC houve crescimento do remanescente ósseo em altura nos três grupos, quando comparados os momentos inicial e final do experimento. Não houve diferença estatística para a altura ( $\mathrm{p}$ $=0,078)$ e para a largura $(p=0,556)$, como demonstram as Tabelas 3 e 4 .

\section{DISCUSSÃO}

A partir dos avanços tecnológicos ocorridos no diagnóstico por imagem, principalmente com a introdução da TC, uma avaliação mais precisa e segura da quanti-

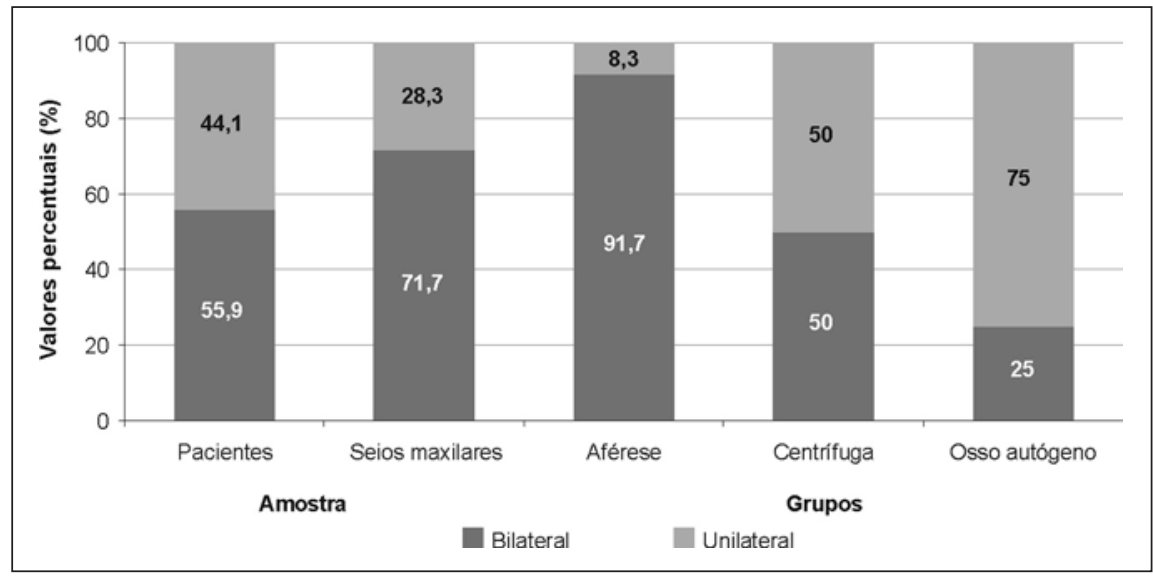

Figura 3. Representação gráfica da distribuição porcentual da amostra e nos três grupos, de acordo com o tipo de cirurgia (bilateral ou unilateral).

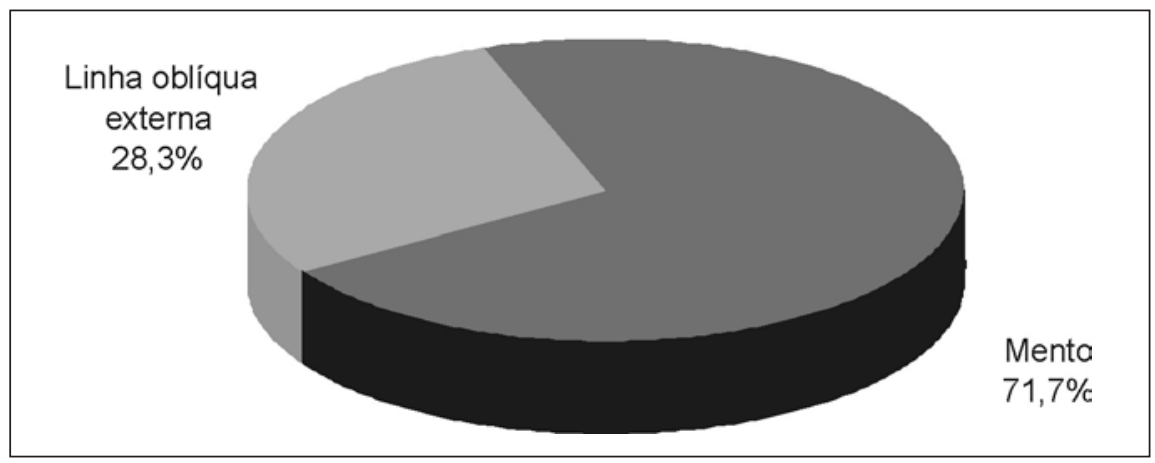

Figura 4. Representação gráfica da distribuição porcentual geral das cirurgias em relação à área doadora.

dade, da qualidade e da densidade óssea presentes para a reabilitação dentofacial com implantes dentários tem sido alcançada. A capacidade tridimensional da TC permite também avaliar os resultados de cirurgias de elevação do assoalho do seio maxilar, identificando inclusive a invagina- ção dos tecidos moles nos locais de enxerto e diagnosticando doenças sinusais ${ }^{(6-9,}$, 20,21). Sabe-se que a implantologia oral apresenta como condição fundamental a necessidade de uma quantidade suficiente de osso saudável no local receptor, tanto em altura quanto em largura ${ }^{(5,6,11,12,16)}$. 
Tabela 1 Médias e desvios-padrão para a altura óssea mensurada pela TC nos três grupos.

\begin{tabular}{|l|c|c|c|}
\hline \multirow{2}{*}{ Grupo } & \multicolumn{2}{|c|}{ Altura óssea } & \multirow{2}{*}{ Diferença } \\
\cline { 2 - 3 } & Inicial & \multicolumn{1}{|c|}{ Final } & $4,1 \pm 2,3$ \\
\hline Aférese & $5,6 \pm 2,1$ & $9,7 \pm 2,7$ & $5,8 \pm 2,8$ \\
Centrífuga & $6,6 \pm 2,6$ & $12,4 \pm 4,0$ & $4,3 \pm 2,1$ \\
Osso autógeno & $6,0 \pm 2,8$ & $10,3 \pm 2,9$ & \\
\hline
\end{tabular}

Tabela 2 Médias e desvios-padrão para a largura óssea mensurada pela TC nos três grupos.

\begin{tabular}{|l|c|r|c|}
\hline \multirow{2}{*}{ Grupo } & \multicolumn{2}{|c|}{ Largura óssea } & \multirow{2}{*}{ Diferença } \\
\cline { 2 - 3 } & Inicial & \multicolumn{1}{|c|}{ Final } & $1,6 \pm 2,2$ \\
Aférese & $6,6 \pm 2,0$ & $8,2 \pm 2,8$ & $2,2 \pm 2,0$ \\
Centrífuga & $8,1 \pm 1,9$ & $10,3 \pm 2,3$ & $2,2 \pm 1,4$ \\
Osso autógeno & $7,3 \pm 1,9$ & $9,5 \pm 1,7$ & \\
\hline
\end{tabular}

Tabela 3 Análise de variância para as diferenças de altura mensurada pela TC nos três grupos.

\begin{tabular}{|c|c|c|c|c|c|c|}
\hline $\begin{array}{l}\text { Fonte de } \\
\text { variação }\end{array}$ & $\begin{array}{l}\text { Graus de } \\
\text { liberdade }\end{array}$ & $\begin{array}{l}\text { Soma de } \\
\text { quadrados }\end{array}$ & $\begin{array}{l}\text { Soma de } \\
\text { quadrados } \\
\text { ajustada }\end{array}$ & $\begin{array}{l}\text { Quadrados } \\
\text { médios } \\
\text { ajustados }\end{array}$ & $\begin{array}{c}\text { Estatística } \\
\mathrm{F}\end{array}$ & $\mathrm{p}$ \\
\hline Grupo & 2 & 30,348 & 30,348 & 15,174 & 2,68 & 0,078 \\
\hline Resíduo & 50 & 282,972 & 282,972 & 5,659 & & \\
\hline Total & 52 & 313,321 & & & & \\
\hline
\end{tabular}

Tabela 4 Análise de variância para as diferenças de largura mensurada pela TC nos três grupos.

\begin{tabular}{|l|c|c|c|c|c|c|}
\hline $\begin{array}{l}\text { Fonte de } \\
\text { variação }\end{array}$ & $\begin{array}{c}\text { Graus de } \\
\text { liberdade }\end{array}$ & $\begin{array}{c}\text { Soma de } \\
\text { quadrados }\end{array}$ & $\begin{array}{c}\text { Soma de } \\
\text { quadrados } \\
\text { ajustada }\end{array}$ & $\begin{array}{c}\text { Quadrados } \\
\text { médios } \\
\text { ajustados }\end{array}$ & $\begin{array}{c}\text { Estatística } \\
\text { F }\end{array}$ & $\mathrm{p}$ \\
\hline Grupo & 2 & 4,482 & 4,482 & 2,241 & 0,59 & 0,556 \\
Resíduo & 50 & 188,942 & 188,942 & 3,779 & & \\
\hline Total & 52 & 193,425 & \multicolumn{7}{|l}{} \\
\hline
\end{tabular}

Deve-se ressaltar que estudos clínicos têm demonstrado que o processo de reabsorção óssea que ocorre após a perda dentária é quatro vezes maior na maxila do que na mandíbula ${ }^{(5)}$. Isto é explicado porque a perda dos dentes superiores e a conseqüente redução das forças mastigatórias que incidem na maxila causam uma diminuição das paredes dos seios maxilares, resultando no aumento do seu tamanho. Além disso, com o avanço da idade e após a perda dos dentes, incluindo a crista alveolar edêndula, a ausência das funções resulta em pneumatização progressiva dos seios $\operatorname{maxilares}^{(5,6,10-12,18)}$.

Com o intuito de possibilitar a reparação de grandes defeitos ósseos provocados por problemas sistêmicos ou por extensa reabsorção óssea devida a múltiplas perdas dentárias, inúmeras pesquisas vêm sendo realizadas envolvendo a utilização de vá- rios materiais que apresentam a principal finalidade de promover a neoformação óssea ${ }^{(\mathbf{5 , 6 , 1 3 , 1 4 )}}$. Entre eles destacam-se os fatores de crescimento, por revelarem, por meio de evidências clínicas, radiológicas e histológicas, que controlam e regulam muitos eventos celulares complexos durante os processos de cicatrização e de remodelação óssea ${ }^{(13,14,17,22)}$, permitindo melhorar as condições locais para a colocação de implantes dentários ${ }^{(\mathbf{1 3 )}}$.

Entre os mecanismos biológicos empregados no controle clínico da formação óssea, a osteoindução e a osteocondução têm sido citadas, principalmente para melhorar as condições ósseas da futura área a receber o implante dentário, através de cirurgias com a utilização de enxertos. A colocação dos implantes exige um rebordo alveolar com espessura mínima de $5 \mathrm{~mm}$ e altura mínima de $10 \mathrm{~mm}^{(5,22)}$. Já a altura média entre a crista alveolar e o assoalho do seio maxilar sadio varia entre 9,3 e 3,23 $\mathrm{mm}$, e a largura varia entre 13,8 e 0,80 $\mathrm{mm}^{(12)}$. Portanto, quando há a necessidade de estimular a formação óssea, a eficácia e o uso específico de determinados fatores de crescimento usados nos enxertos ósseos podem se transformar em um excelente método terapêutico, de resultados positivos já comprovados ${ }^{(5,6,13,14,22)}$.

Acreditamos que para grupos selecionados de pacientes a aférese seja um bom método de aquisição do PRP. Por ser considerado um método recente na odontologia, apresenta algumas dificuldades quanto ao elevado custo e à necessidade de pessoal especializado. Estudos anteriores demonstraram que o sistema de aférese para coleta do PRP tem como o objetivo aumentar a quantidade de fatores de crescimento $^{(6,13-15)}$.

Vários são os materiais utilizados nos enxertos ósseos, sendo os mais comuns os enxertos aloplásticos (tricálcio, fosfato, hidroxiapatita), os alógenos e xenógenos (osso bovino desproteinado desmineralizado) e o osso autógeno ${ }^{(1)}$.

De acordo com os tipos de enxertos utilizados, os pacientes submetidos à cirurgia de elevação do assoalho do seio maxilar foram divididos em três grupos: 12 pacientes receberam enxerto de osso autógeno com PRP obtido por aférese; 10 pacientes receberam enxerto de osso autógeno com PRP obtido por centrifugação; e 12 pacientes receberam enxerto somente de osso autógeno, num total de 34 pacientes e 53 seios maxilares operados.

Ao observarmos os resultados tomográficos computadorizados obtidos no presente estudo, pudemos observar que durante as cirurgias de elevação do assoalho do seio maxilar os enxertos de osso autógeno foram obtidos em $71,7 \%$ das vezes da região do mento mandibular, enquanto somente $28,3 \%$ das vezes a região doadora correspondeu à linha oblíqua externa. Esses resultados vêm ao encontro de vários estudos que evidenciam a sínfise mandibular como uma fonte singularmente benéfica, por fornecer osso cortical e medular necessários para a osteoindução e osteocondução, portanto, de qualidade óssea superior aos demais locais considerados áreas doadoras dos enxertos ${ }^{(1,11,17)}$. 
Por meio dos dados demonstrados pelas médias e pelos desvios-padrão da formação óssea, observou-se que houve crescimento em altura nos três grupos, quando comparados os momentos inicial e final, apesar de estatisticamente não significante $(\mathrm{p}=0,078)$.

São inúmeras as pesquisas realizadas até hoje que concordam em afirmar que, pelos seus aspectos biológicos, o PRP é uma fonte autógena altamente concentrada de fatores de crescimento, sendo que a sua utilização nas reconstruções maxilares está associada a uma melhor integração dos enxertos $^{(15,21-29)}$. Deve-se ressaltar também que o PRP adicionado ao enxerto pode promover uma formação de rede de fibrina responsável pela estabilidade do enxerto, estimulando a osteocondução ${ }^{(\mathbf{1 9 , 2 5 )}}$.

Os resultados observados nos enxertos com osso autógeno sem PRP da nossa amostra mostraram que esse crescimento em altura ficou entre as médias finais obtidas pelo método de centrifugação e pelo de aférese, o que foi apresentado também em outros estudos ${ }^{(\mathbf{1 , 5}, 16)}$. Torna-se necessário citar que alguns autores acreditam que o melhor modo de reconstrução do osso nos pacientes que necessitam de implantes dentários seja o enxerto autógeno ${ }^{(5,19)}$.

Por meio dos dados demonstrados pelas médias e pelos desvios-padrão da formação óssea, observou-se que houve crescimento em largura nos três grupos observados, quando comparados os momentos inicial e final, apesar de estatisticamente não significante $(\mathrm{p}=0,556)$.

Um estudo realizado para verificar a associação do PRP ao osso autógeno juntamente com o beta-tricálcio fosfato demonstrou uma regeneração óssea vertical e horizontal de cerca de $4 \mathrm{~mm}^{(\mathbf{2 8})}$.

Apesar dos nossos resultados não serem estatisticamente significantes, evidências clínicas têm mostrado a eficácia dos enxertos de osso autógeno, principalmente aqueles associados a fatores indutores de crescimento ósseo, como o PRP, alterando a altura e a largura necessárias para a reconstrução protética do arcabouço maxilofacial, através de implantes osteo- integrados, porque na odontologia atual busca-se cada vez mais devolver aos pacientes edêntulos a sua capacidade mastigatória e estética, e, conseqüentemente, promovendo a integridade dos vários elementos que compõem o sistema estomatognático.

\section{REFERÊNCIAS}

1. Kato Segundo T. Avaliação dos tipos de enxerto ósseo e seus homólogos para aumento de rebordo alveolar e levantamemto de seio maxilar. (Monografia de especialização). Belo Horizonte, MG: Universidade Federal de Minas Gerais, 1998.

2. Robertson WGCB, Passeri LA. Elevação do seio maxilar e enxertos para colocação de implantes dentais. Robrac 2000;27:54-7.

3. Scarso Filho J, Barreto MA, Mendonça RG, Dinato JC. In: Dinato JC, Polido WD. Implantes osseointegrados: cirurgia e prótese. São Paulo, SP: Ed. Artes Médicas, 2001:315-42.

4. Whitman DH, Berry RL, Green DM. Platelet gel: an autologous alternative to fibrin glue with applications in oral and maxillofacial surgery. J Oral Maxillofac Surg 1997;55:1294-9.

5. Buser D, Hoffmann B, Bernard JP, Lussi A, Mettler D, Schenk RK. Evaluation of filling materials in membrane-protected bone defects. A comparative histomorphometric study in the mandible of miniature pigs. Clin Oral Implants Res 1998;9:137-50.

6. Garg AK. Augmentation grafting of the maxillary sinus for placement of dental implants: anatomy, physiology, and procedures. Implant Dent 1999; 8:36-46.

7. Dutra V. Diagnóstico por imagens em implantodontia. In: Dinato JC, Polido WD. Implantes osseointegrados: cirurgia e prótese. São Paulo, SP: Ed. Artes Médicas, 2001.

8. Chilvarquer I, Chilvarquer LW. Imagenologia da osteo-integração moderna. In: Gomes LA. Implantes osseointegrados. Técnica e arte. $1^{a} \underline{a}$ ed. São Paulo, SP: Ed. Santos, 2002.

9. Misch CE. Implantes dentários contemporâneos. $2^{\mathbf{a}}$ ed. São Paulo, SP: Ed. Santos, 2000.

10. Watzek G, Ulm C, Haas R. Anatomic and physiologic fundamentals of sinus floor augmentation. In: Jensen OT, ed. The sinus bone graft. Chicago, IL: Quintessence, 1999:31-47.

11. Matte EW. Enxerto de sínfise mandibular para recuperação de rebordos reabsorvidos e colocação de implantes osseointegrados. (Dissertação de Mestrado). Bauru, SP: Universidade de São Paulo, 2000.

12. Lekholm U. A eficácia da osseointegração para o paciente parcialmente edêntulo. In: Nevins M, Mellonig JT, eds. Implantoterapia. $1^{\underline{a}}$ ed. São Paulo, SP: Quintessência Editora Ltda., 2003:22-5.

13. Mugnolo GM. Efectos de los factores de crecimiento sobre el hueso: sus implicancias para la implantologia. Rev Soc Odont de la Plata 1999;12:614.

14. Herndon DN, Nguyen TT, Gilpin DA. Growth factors. Local and systemic. Arch Surg 1993;128: 1227-33.
15. Lozada JL, Caplanis N, Proussaefs P, Willardsen J, Kammeyer G. Platelet-rich plasma application in sinus graft surgery: Part I - Background and processing techniques. J Oral Implantol 2001;27:3842.

16. Marx RE, Carlson ER, Eichstaedt RM, Schimmele SR, Strauss JE, Georgeff KR. Platelet-rich plasma. Growth factor enhancement for bone grafts. Oral Surg Oral Med Oral Pathol Oral Radiol Endod 1998;85:638-46.

17. Matsumoto MA. Análise microscópica de rebordos alveolares maxilares reconstruídos com enxertos autógenos de crista ilíaca e região. (Dissertação de Mestrado). Bauru, SP: Universidade de São Paulo, 1999.

18. Vasconcelos LW, Lima EG, Takagui RM, Francischone CE. Enxerto ósseo autógeno em seio maxilar com implantes imediatos. Rev Assoc Paul Cir Dent 1998;52:35-41.

19. Raghoebar GM, Timmenga NM, Reintsema H, Stegenga B, Vissink A. Maxillary bone grafting for insertion of endosseous implants: results after 12 124 months. Clin Oral Implants Res 2001;12:279 86.

20. Uchida Y, Goto M, Katsuki T, Akiyoshi T. A cadaveric study of maxillary sinus size as an aid in bone grafting of the maxillary sinus floor. J Oral Maxillofac Surg 1998;56:1158-63.

21. Weibrich G, Kleis WK, Kunz-Kostomanolakis M, Loos AH, Wagner W. Correlation of platelet concentration in platelet-rich plasma to the extraction method, age, sex, and platelet count of the donor. Int J Oral Maxillofac Implants 2001;16:693-9.

22. Silva JCL. Biologia e aplicação clínica das proteínas osseas morfogenéticas. (Dissertação de Mestrado). São Paulo, SP: Universidade de São Paulo, 1999.

23. Danesh-Meyer MJ, Filstein MR, Shanaman R. Histological evaluation of sinus augmentation using platelet rich plasma (PRP): a case series. J Int Acad Periodontol 2001;3:48-56.

24. Beltrão GC, Andrade MGS. Aspectos biológicos da utilização do gel de plasma rico em plaquetas nas reconstruções maxilares com enxertos. BCI: Rev Bras Cirurg Implant 2001/2002;9:324-8.

25. Froum SJ, Wallace SS, Tarnow DP, Cho SC. Effect of platelet-rich plasma on bone growth and osseointegration in human maxillary sinus graft: three bilateral case reports. Int J Periodontics Restorative Dent 2002;22:45-53.

26. Yamamoto MK. Efeitos do plasma rico em plaquetas na reparação alveolar em ratos. (Dissertação de Mestrado). São Paulo, SP: Universidade de São Paulo, 2002.

27. Andriolo AR, Cardoso R, Gregori C, Andriolo A. Plasma rico em plaquetas (PRP) como coadjuvante da reparação óssea. Rev Assoc Paul Cir Dent 2002;56:418

28. Moro G, Casini V, Bastieri A. Use of platelet-rich plasma in major maxillary sinus augmentation. Minerva Stomatol 2003;52:267-71.

29. Jakse N, Tangl S, Gilli R, et al. Influence of PRP on autogenous sinus grafts. An experimental study on sheep. Clin Oral Implants Res 2003;14:578 83. 